\title{
Body Remember: A Memoir
}

Fries, Kenny (2003)

Ann Arbor: University of Wisconsin Press.

"I am the freak in the centre of all three rings, as well as the star of the sideshow, in a travelling circus that should have closed down a very long time ago (p175)". This sentence succinctly describes Kenny Fries' view of himself in relation to the world in which he lives and yet is not truly part of. He dreams of a world where "connotations of disability are not pejorative" and labels of disability become the names of constellations. He is uniquely qualified to write on the social construct of disability as in the lotto of life he drew three aces, disabled, Jewish and homosexual; in a world that marginalises minorities he is truly looking from the outside in. However in the Body Remember he instead looks at the issue of disability from a more personal viewpoint, his own experience.

Body Remember is a memoir. It is an extension of a true autobiography because Fries does not just relate his story instead he explores the events in his life that are lodged in his memory and seeks to explain why those moments are significant while others are not. A memoir generally centres on a conflict or a quest and attempts to resolve it. Fries' quest is one of understanding, how his love for his childhood doctor relates to the pain his body remembers, how his love for his family relates to the abuse he received from his father and brother and finally how his concept of self equates to how others perceive him.

Fries' story differs from many other autobiographical stories. Fries is not looking for a way to "be normal" he is instead looking for a sense of belonging within himself. A "home" where he feels connected to himself, his disability, his sexuality, his religion and his past. "I think home is not necessarily land, land not necessarily home. To have an identity one must have a home", and this ultimately is the conflict that exists at the heart of the story, "Who am I" and "Why am I the way that I am". The role of antagonist is played by Fries' own failure to find a home and therefore denying him an identity.

Fries' journey is hard to travel in some parts, but his childhood recollections are truly memorable taking the reader into the spontaneous, accepting mind of a child whose ambivalence at the base of every relationship follows him into adulthood. It is important to remember that a memoir struggles with the truth as few people can truly remember clear details of their life. This is even more apt in Fries' case as he admits that he has very little memory of his childhood and is forced to rely on obscure medical files that explain nothing 
beyond the facts of his disability. In relating his childhood Fries is forced to step out of the role of protagonist and solely into the role of narrator. "It is with a mixture of horror and disbelief that I remember that young infant in the incubator, that body on the operating table was me”.

If the writing of a life story is productive rather than reflective of self then Fries' memory is tainted by who he is today. Fries has spent his life seeing himself through other's eyes. As a child it was through the eyes of his doctor and his family, his coming of age was shaped by the view of his sexual partners and finally his realisation that the secret to his identity was within. "I need a silence quiet enough, deep enough, so I can begin to hear what it is I think, to know what it is I feel, to gain some control over what has been going on ". This knowledge of self as seen through others means that his thoughts are hard to ascertain and his ability to self assess is poor. "I am like Narcissus, looking for my reflection to be given back to me from the pool that ripples before my eyes.”

In producing a particular account of his life story the writer becomes accountable for the reader's expectations. Fries remembers what he wants to remember and he glosses over what he has forgotten or chooses to ignore. The complex relationship that exists as Fries takes on the roles of antagonist, protagonist and narrator results in a story that is disjointed and vague and this serves to confuse the reader. His discovery that he is "unable to find answers for the child that he was because “sometimes questions don't have answers” itself makes nonsense of the role of the memoir within autobiography. The process of self-discovery is made to seem pointless, major discoveries rendered unimportant and the disjointed nature of Fries' quest fail to reveal an inner meaning or even a final destination. However, the story is full of wonderful imagery and a true voyeurs look into the unique world of Kenny Fries and for that alone is worth the journey.

\section{Caroline Slade}

Student, School of Human Services \& Social Work, Griffith University 